J. Asiat. Soc. Bangladesh, Sci. 40(1): 1-7, June 2014

\title{
MEASUREMENT OF EFFECTIVE DOSE TO PATIENT DURING INTERVENTIONAL CARDIAC PROCEDURE
}

\author{
M.M.M. SIRAZ ${ }^{1}$, ALEYA BEGUM, R.K.KHAN, A.HOQUE AND A.BEGUM ${ }^{2}$ \\ Health Physics Division, Atomic Energy Centre, Dhaka-1000, Bangladesh \\ ${ }^{2}$ Department of Physics, University of Dhaka, Dhaka-1000, Bangladesh
}

\begin{abstract}
Interventional cardiac procedures result in substantial patient radiation dose due to prolonged fluoroscopy time and radiographic exposure. Patient dose measurement is performed in two catheterization laboratories in Square Hospital Ltd, Dhaka. A total of 50 patients of Square Hospital is included in this study. TLDs are used for the measurement of the dose received by patients during interventional cardiology at Square Hospital, Dhaka. Patients, who underwent CAG, PTCA, and (CAG with PTCA) have average effective dose $3.30 \mathrm{mSv}$ with a range from 0.96 to $9.12 \mathrm{mSv}, 24.14 \mathrm{mSv}$ with a range from $7.56 \mathrm{mSv}$ to $56.81 \mathrm{mSv}$ and $25.56 \mathrm{mSv}$ with a range from $1.21 \mathrm{mSv}$ to $95 \mathrm{mSv}$ respectively. Our results correspond well with those obtained by authors in other countries of the world. This study would be useful to establish a database of the patient's dose for CAG and PTCA. This may lead cardiologists and scientists to adopt necessary safety measures for reducing exposure to patients and occupational workers.
\end{abstract}

Key words: Ionizing radiation, Effective dose, Interventional cardiac procedure, Cardiac patient, TLD, Biological effects of ionizing radiation

\section{Introduction}

Radiation protection for patients and staff is one of the main issues in Interventional Radiology (IR). United Nations Scientific Committee on the Effects of Atomic Radiation (UNSCEAR), International Commission on Radiation Protection (ICRP) and International Atomic Energy Agency (IAEA) have devoted significant time over the last years to improve radiation safety in IR. To improve radiation protection in IR, assessment of exposure situation is essential which necessitates patient dose measurement. The introduction of cardiac catheterization has brought about advances in diagnostic radiology and its use has been increasing rapidly. The medical use of ionizing radiation, while offering great benefit to patients, also contributes significantly to radiation exposure of individuals and populations (UNSCEAR 1993 and 2000 and EURATOM 1997). Use of radiation for medical examinations and tests is the largest artificial source of radiation exposure. According to the results published by the United Nations Scientific Committee on the Effects of Atomic Radiation (UNSCEAR), interventional procedures contribute only $1 \%$ to the frequency of radiation use on the medical field whereas their contribution to collective dose is 10\% (NRPB 1990). When complex procedures are performed or procedures are repeated for the same patient, high radiation dose levels can

\footnotetext{
${ }^{1}$ Corresponding author: Email: mahfuzsiraz1985@yahoo.com
} 
occur because procedures often require long fluoroscopy time and a large number of images. According to UNSCEAR from 1992 to 1995 in the USA, there were 26 reports to the Food and Drug Administration (FDA), of radiation induced skin injuries from fluoroscopy. By 1999, the FDA documented some 50 cases of radiation induced burns, many involving cardiac procedures. Reports (Sovik et al. 1996) from the FDA's voluntary registry and other worldwide studies are continuing to detect more incidents of skin burn following Interventional Cardiology(IC).

Justification and optimization in IR are highly required by the international standards. Special attention should be given to the quality assurance programs (EURATOM 1997) including quality control measures and patient-dose assessment in IR.

Radiation in the catheterization lab is generated using two different modes: fluoroscopy and cine angiography (cine). Fluoroscopy is used for catheter placement and it involves $95 \%$ of the total $\mathrm{x}$-ray operation time but only causes $40 \%$ of the total radiation exposure to staff and patients. Cine is used to acquire diagnostic images and to generate a permanent record of the procedure. Although it is representing only $5 \%$ of the total x-ray tube operation time, $60 \%$ of the total radiation exposure to staff and patients occur during cine.

The aim of the present study is to monitor the effective dose of the patients during diagnostic and interventional cardiology procedures mainly CAG and PTCA and to compare with published literature on patient dosimetry in IC, discuss discrepancies of results and comment on risks to patients and strategies to minimize patient radiation doses.

\section{Materials and Methods}

In two catheterization laboratories in Square Hospital, Dhaka, patients' effective dose has been collected. Thirty four patients who underwent CAG, four patients who underwent PTCA and ten patients who underwent CAG plus PTCA are enrolled in this study. Another two patients who underwent different cardiac treatment (PTMC, PPC) are also enrolled in this study. Thus a total of 50 patients is included in this study.

Effective dose to patients was measured using calibrated Harshaw TLD cards. The Harshaw Thermoluminescent dosimeters (TLD) reader (Model 4500) in Health physics division (HPD), Atomic Energy Center (AEC) at Dhaka has been used for reading out the TLD cards.

\section{Results and Discussion}

Statistical analysis of height, weight and age of the patients for the procedures are presented in Table 1. The number of female patients was observed to be less in all the cases. In Square Hospital average height of patients who underwent CAG and PTCA was $162.12 \mathrm{~cm}$ and $158.75 \mathrm{~cm}$ respectively. 
Table 1. Patient information and their dose distribution during different cardiac procedure.

\begin{tabular}{|c|c|c|c|c|c|c|c|c|c|}
\hline \multirow{3}{*}{$\begin{array}{l}\text { Patient's } \\
\text { information }\end{array}$} & \multicolumn{9}{|c|}{ Name of the cardiac procedure } \\
\hline & \multicolumn{3}{|c|}{$\mathrm{CAG}$} & \multicolumn{3}{|c|}{ PTCA } & \multicolumn{3}{|c|}{ CAG and PTCA } \\
\hline & Average & Min & $\operatorname{Max}$ & Average & Min & Max & Average & Min & $\operatorname{Max}$ \\
\hline Height $(\mathrm{cm})$ & 162.12 & 146 & 176 & 158.75 & 150 & 167 & 163.9 & 154 & 172 \\
\hline Weight $(\mathrm{kg})$ & 66.50 & 39 & 99 & 59.00 & 58 & 61 & 66.95 & 59 & 92 \\
\hline Age (yrs) & 56.21 & 40 & 71 & 60.25 & 55 & 66 & 56.7 & 40 & 70 \\
\hline
\end{tabular}

Those who went CAG and PTCA simultaneously had average height of $163.9 \mathrm{~cm}$. Their average weights were $66.50 \mathrm{~kg}, 59.00 \mathrm{~kg}$ and $66.95 \mathrm{~kg}$ respectively and average age were $56.21,60.25$ and 56.70 years respectively. Total number of male patients who had undergone CAG and PTCA were 25 and 3 respectively and number of female patients in CAG and PTCA were 9 and 1 respectively.

The distribution of patients at different effective dose range is shown in Figs.1 and 2 which show that 6 patients who had undergone CAG were in the dose range of 0 to 1 $\mathrm{mSv}, 8$ patients were in the dose range of 1 to $2 \mathrm{mSv}, 4$ patients were in the dose range of 2 to $3 \mathrm{mSv}$ and 8 patients were in the dose range of 3 to $5 \mathrm{mSv}$. Thus it is seen that most of the patients were in lower dose range. But patients who had undergone PTCA and $(\mathrm{CAG}+\mathrm{PTCA})$ were mostly in the high dose range, i.e., in the range of 6 to $95 \mathrm{mSv}$.

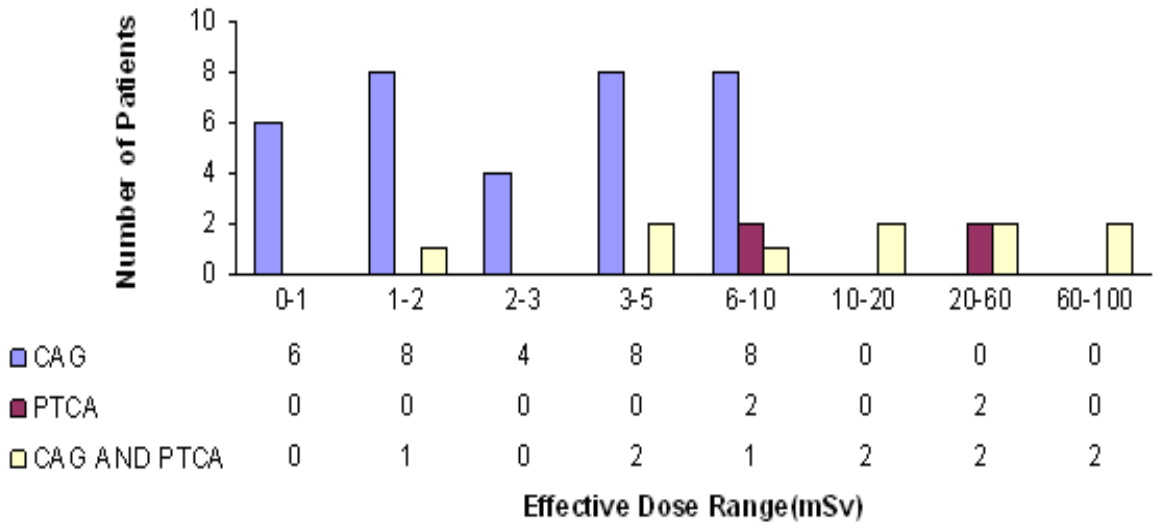

Fig.1. Effective dose distribution for CAG, PTCA and CAG plus PTCA. 


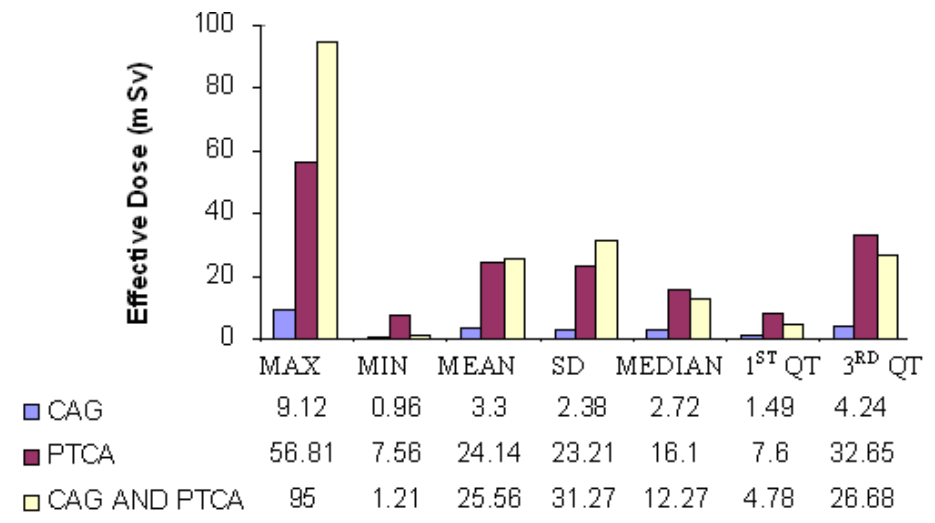

Fig.2. Statistical analysis of effective dose of patients.

The mean effective dose to patients in CAG is $3.3 \mathrm{mSv}$, where maximum and minimum values were 9.12 and $0.96 \mathrm{mSv}$ respectively. It is also found that median, $1^{\text {st }}$ and $3^{\text {rd }}$ quartile values for CAG are 2.72, 1.49 and $4.24 \mathrm{mSv}$ respectively. For PTCA the mean effective dose was $24.14 \mathrm{mSv}$, where maximum and minimum values were 56.81 and $7.56 \mathrm{mSv}$ respectively. The median, $1^{\text {st }}$ and $3^{\text {rd }}$ quartile values for PTCA were $16.1,7.6$ and $32.65 \mathrm{mSv}$ respectively. There were some patients who had undergone CAG and PTCA simultaneously. For such cases the mean effective dose was $25.56 \mathrm{mSv}$, where maximum and minimum values were $95 \mathrm{mSv}$ and $1.21 \mathrm{mSv}$ respectively. The median, $1^{\text {st }}$ and $3^{\text {rd }}$ quartile values in this cases were $12.27,4.78$ and $26.68 \mathrm{mSv}$ respectively.

Effective dose values found for patients in Bangladesh in this study are reasonable compared to those found in other countries in the world which lies in the range from 3 to $22 \mathrm{mSv}$ in CAG, from 10 to $31 \mathrm{mSv}$ for PTCA and from 5 to $41 \mathrm{mSv}$ for CAG with PTCA (Table 2).

It has been found that patients who have coronary angioplasty were involved with high effective dose than those who have coronary angiography due to long fluoroscopy time and a large number of images.

In this study it is observed that most of the patients were in low effective dose region from 0 to $6 \mathrm{mSv}$. But a small but not negligible amount of patients were in high dose region. This exposure to high radiation doses can lead to severe skin and lesion injuries in the long run.

Another important observation is that mean values of the occupational doses in catheterization laboratories could provide an incorrect estimate of the real radiological risk. 
Another very significant observation is that most of the patients went through cardiac procedure having height, weight and age within the range 160-170 cm, 60-70 kg, 50-60 year respectively.

Table 2. Studies reporting effective dose of diagnostic and interventional cardiac procedures.

\begin{tabular}{|c|c|c|c|c|c|}
\hline \multirow{2}{*}{ Previous Studies } & \multirow{2}{*}{ Year } & \multirow{2}{*}{ Group } & \multicolumn{3}{|c|}{ Mean effective dose ( $\mathrm{mSv}$ ) } \\
\hline & & & $\mathrm{CAG}$ & PTCA & $(\mathrm{CAG}+\mathrm{PTCA})$ \\
\hline Karppinen et al. & 1995 & $\ldots$ & $\ldots$ & $\ldots$ & 10.6 \\
\hline Leung and Martin & 1996 & $\ldots$ & 3.1 & & $\ldots$ \\
\hline \multirow{2}{*}{ Broadhead et al. } & \multirow{2}{*}{1997} & Room A & 9.4 & 14.2 & $\ldots$ \\
\hline & & Room B & 4.6 & 10.2 & $\ldots$ \\
\hline Betsou et al. & 1998 & $\ldots$ & 5.6 & 6.9 & 9.3 \\
\hline Harrison et al. & 1998 & $\ldots$ & 3.4 & $\ldots$ & $\ldots$ \\
\hline Neofotistou et al. & 1998 & $\ldots$ & $4.6-15.8$ & $\ldots$ & $5.4-41.0$ \\
\hline Katritsis et al. & 2000 & $\ldots$ & 5.0 & 6.6 & 13.6 \\
\hline Lobotessi et al. & 2001 & $\ldots$ & 13.2 & & $\ldots$ \\
\hline \multirow{2}{*}{ Delichas et al. } & \multirow{2}{*}{2003} & Hospital A & 22.7 & 30.5 & . . \\
\hline & & Hospital B & 17.9 & 14.7 & . . \\
\hline Efstathopoulos et al. & 2003 & $\ldots$ & 5.0 & $\ldots$ & 14.8 \\
\hline Hunold et al. & 2003 & $\ldots$ & 2.3 & $\ldots$ & $\cdots$ \\
\hline \multirow{2}{*}{ Sandborg et al. } & \multirow{2}{*}{2004} & Femoral & 6.8 & · & 8.6 \\
\hline & & Radial & 9.2 & & 13.5 \\
\hline \multirow{4}{*}{ Viktorie Stisova. } & \multirow{4}{*}{2004} & Workplace A1 & 8.8 & . & $\cdots$ \\
\hline & & Workplace A2 & 3.6 & $\ldots$ & 9.7 \\
\hline & & Workplace B & 7.9 & $\ldots$ & 15.3 \\
\hline & & Workplace C & 2.7 & $\ldots$ & 5.7 \\
\hline Vijayalakshmi et al. & 2007 & $\ldots$ & 4.4 & & \\
\hline Present study & 2011 & $\ldots$ & 3.30 & 24.14 & 25.56 \\
\hline
\end{tabular}

Our results correspond well with the results obtained by authors of other countries in the world (Table 2).

Diagnostic and interventional catheterization procedure has been increasing day by day. It is paramount important that radiation protection in the catheterization laboratory must be a matter of primary concern. Exposure to ionization radiation may result in adverse health effect on both cardiologists directly and on their progeny. The occupational doses of interventional cardiologists tend to be higher compared to other medical specialists due to increase of interventional technique. The physicians are dramatically unaware of dose, long-term risks and population health impact caused by the use of medical ionizing radiation. Patient radiation doses vary widely among the different interventional cardiology procedures and also among published studies. This variation of radiation doses is due to variation of physical parameters of the patient, procedure, physician, fluoroscopic equipment, etc. Nevertheless, IC procedures can subject patients to 
considerable radiation doses and efforts to minimize patient exposure should always be undertaken.

\section{References}

Betsou, S., E.P. Efstathopoulos, D. Katritsis, K. Faulkner and G. Panayiotakis. 1998. Patient radiation doses during cardiac catheterization procedures. Br J Radiol. 71: 634-639.

Broadhead, D.A., C.L. Chapple, K. Faulkner, M.L. Davies and H. McCallum. 1997. The impact of cardiology on the collective effective dose in the North of England. Br J Radiol. 70: 492497.

Delichas, M.G., K. Psarrakos, E. Molyvda Athanassopoulou, G. Giannoglou, K. Hatziioannou and E. Papanastassiou. 2003. Radiation Doses to Patients Undergoing Coronary Angiography and Percutaneous Transluminal Coronary Angioplasty. Radiation Protection Dosimetry. 103: $149-154$.

Efstathopoulos, E.P., S.S. Makrygiannis, S. Kottou, E. Karvouni, E. Giazitzoglou, S. Korovesis, E. Tzanalaridou, P.D. Raptou and D.G. Katritsis. 2003. Medical personnel and patient dosimetry during coronary angiography and intervention. Phys Med Biol. 48: 3059-3068.

EURATOM (European Union), Council Directive 97/43/ of 30 June 1997. Health protection of individuals against the dangers of ionizing radiation in relation to medical exposure (repealing Directive 84466 EURATOM, O.J. No L 2651, 5.10.1984). Official J. Eur. Communities L.180: 22-27.

Harrison, D., M. Ricciardello and L. Collins. 1998. Evaluation of radiation dose and risk to the patient from coronary angiography. Aust N Z J Med. 28: 597-603.

Hunold, P., F.M. Vogt, A. Schmermund, J.F. Debatin, G. Kerkhoff, T. Budde, R. Erbel, K. Ewen and J. Barkhausen. 2003. Radiation exposure during cardiac CT: effective doses at multidetector row CT and electron-beam CT. Radiology. 226: 145-152.

International Basic Safety Standards for protection against ionizing radiation and for the safety of radiation sources. Safety Series No. 115. (IAEA)

Karppinen, J., T. Parviainen, A. Servomaa and T. Komppa. 1995. Radiation risk and exposure of radiologists and patients during coronary angiography and percutaneous transluminal coronary angioplasty (PTCA). Radiat Prot Dosim. 57: 481-485.

Katritsis, D., E. Efstathopoulos, S. Betsou, S. Korovesis, K. Faulkner, G. Panayiotakis and M.M. Webb-Peploe. 2000. Radiation exposure of patients and coronary arteries in the stent era: a prospective study. Catheter Cardiovasc Interv. 51: 259-264.

Leung, K.C. and C.J. Martin.1996. Effective doses for coronary angiography. Br J Radiol. 69: 426431.

Lobotessi, H., A. Karoussou, V. Neofotistou, A. Louisi and V. Tsapaki. 2001. Effective dose to a patient undergoing coronary angiography. Radiat Prot Dosimetry. 94: 173-176.

Neofotistou, V., A. Karoussou, H. Hobotesi and K. Hourdakis. 1998. Patient dosimetry during interventional cardiology procedures. Radiat Prot Dosim. 80: 151-154.

National Radiological Protection Board (NRPB) and Royal College of Radiologists (RCR). 1990. Patient dose reduction in diagnostic radiology. Report of the RCR and NRPB, Documents of the NRPB 1(3).

Sandborg, M., S.G. Fransson and H. Pettersson. 2004. Evaluation of patient-absorbed doses during coronary angiography and intervention by femoral and radial artery access. Eur Radiol. 14: $653-658$.

Sovik, E., N.E. Klow, J. Hellesnes and J. Lykke.1996. Radiation-induced skin injury after percutaneous transluminal, coronary angioplasty. Case report. Acta Radiol. 37: 305-306. 
UNSCEAR. 2000. Sources and effects of ionising radiation. United Nations Scientific Committee on the Effects of Atomic Radiation Report to the General Assembly with Scientific Annexes.

UNSCEAR. 1993. Sources and effects of ionising radiation. Report to the General Assembly, with scientific annexes. New York, UN.

Viktorie Stisova. 2004. Effective Dose to Patient during Cardiac Interventional Procedures (Prague Workplaces). Radiation Protection Dosimetry. 111: 271-274.

Vijayalakshmi, K., D. Kelly, C.L. Chapple, D. Williams, R. Wright, M.J. Stewart, J.A. Hall, A. Sutton, A. Davies, J. Haywood and M.A. De Belder. 2007. Cardiac catheterisation: radiation doses and lifetime risk of malignancy. Heart. 93: $370-371$.

(Received revised manuscript on 27 February 2014) 